\title{
Neuropsychological differences between types of multiple sclerosis: relapsing remitting versus primary progressive
}

\author{
Cristina De-la-Peña ${ }^{1 *}$, Nicolás Parra-Bolaños ${ }^{2}$, Elena Bernabéu-Brotóns ${ }^{3}$, and Juliana Fernández-Medina ${ }^{4}$ \\ ${ }^{1}$ Department of Educational Psychology and Psychobiology, Universidad Internacional de La Rioja (UNIR), Madrid, España; ${ }^{2}$ Neuroscience and \\ Education Laboratory, Asociación Educar Para El Desarrollo Humano. Buenos Aires, Argentina; ${ }^{3}$ Faculty of Education and Psychology, Universidad \\ Francisco de Vitoria, Madrid, España; ${ }^{4}$ Instituto de Neurociencias y Neurorrehabilitación Aplicada y Funcional, Medellín, Colombia
}

\begin{abstract}
Background: Multiple sclerosis (MS) is a neurodegenerative disease whose clinical deterioration is observed at a physical, cognitive, and socio-emotional level, affecting the quality of life of the patient. Several scientific studies show early cognitive alterations in MS and profiles of different cognitive affectation according to the clinical form of the disease. Objective: The objective of the study was to analyze the existence of significant differences between relapsing remitting MS (RRMS) and primary progressive MS (PPMS) in neuropsychological processes such as attention, memory, language, visuoperception, executive function, and processing speed. Methods: The sample consisted of 20 patients with MS with chronological ages between 20 and 50 years of both sexes belonging to the Psique de Medellin Foundation, who were administered the paced auditory serial addition test and the digit-symbol test to assess attention, the complex figure of Rey to evaluate memory, the Boston test, and verbal fluency to assess language, complex figure of Rey copy for visuoperception, Wisconsin to assess executive function, and trail making test to measure processing speed. A descriptive, inferential, and transversal design was used. Results: There are no significant differences between the scores of patients with RRMS and PPMS in any assessed neuropsychological process. Conclusion: Knowing the neuropsychological profile of MS in early stages can be useful as an indicator of prognosis and to suggest therapeutic and follow-up strategies in patients with RRMS and PPMS.
\end{abstract}

Key words: Multiple sclerosis. Attention. Memory. Language. Executive function.

\section{Diferencias neuropsicológicas entre tipos de esclerosis múltiple: remitente recurrente vs progresiva primaria}

\section{Resumen}

Antecedentes: La esclerosis múltiple (EM) es una enfermedad neurodegenerativa cuyo deterioro clínico se observa en los planos físico, cognitivo y socioemocional, incidiendo en la calidad de vida del paciente. Diversos estudios científicos muestran alteraciones cognitivas tempranas en la EM y perfiles de afectación cognitiva distintos,según sea la forma clínica de la enfermedad. Objetivo: Analizar la existencia de diferencias significativas entre la EM remitente recurrente y la EM progresiva primaria en procesos neuropsicológicos, como atención, memoria, lenguaje, visopercepción, función ejecutiva y velocidad de procesamiento. Métodos: La muestra se

Correspondence:

*Cristina de la Peña Álvarez

E-mail: cristina.delapena@unir.es
Available online: $21-10-2020$ Rev Mex Neuroci. 2020;21(5):192-198 www.revmexneurociencia.com 1665-5044/ @ 2020 Academia Mexicana de Neurología A.C. Published by Permanyer. This is an open access article under the CC BY-NC-ND license (http://creativecommons.org/licenses/by-nc-nd/4.0/). 
integró con 20 pacientes con esclerosis múltiple y edades cronológicas de 20 a 50 años de ambos sexos pertenecientes a la Fundación Psique de Medellín, sometidos a la administración del PASAT y la prueba dígito-símbolo para valorar la atención, la Figura Compleja de Rey para evaluar la memoria, la prueba de Boston y Fluidez Verbal para valorar el lenguaje, la Figura Compleja de Rey (copia para visopercepción), la prueba de Wisconsin para valorar la función ejecutiva y el Trail Making Test para medir la velocidad de procesamiento. Se utilizó un diseño descriptivo, inferencial y transversal. Resultados: No existen diferencias significativas entre las puntuaciones de pacientes con esclerosis múltiple remitente recurrente y esclerosis múltiple progresiva primaria en ningún proceso neuropsicológico valorado. Conclusiones: Puede ser de utilidad conocer el perfil neuropsicológico de la EM en fases tempranas como indicador de pronóstico y para sugerir formas terapéuticas y de seguimiento en pacientes con esclerosis múltiple remitente recurrente y esclerosis múltiple progresiva primaria.

Palabras clave: Esclerosis múltiple. Atención. Memoria. Lenguaje. Función ejecutiva.

\section{Introduction}

Multiple sclerosis (MS) is a neurodegenerative pathology that affects the central nervous system, characterized by presenting heterogeneity of symptoms and progressive disability that impairs the quality of life of patients ${ }^{1}$.

Nowadays, various research studies ${ }^{2,3}$ show that MS is a demyelinating disease in which immune processes are altered, unknown etiology but involving an interplay between genetic and environmental factors.

MS is clinically characterized by relapses and/or progression ${ }^{4}$, being relapses or not associated with progression. Relapses refer to acute or subacute episodes of neurological dysfunction that may or may not be followed by a remission, spontaneously or after treatment, resulting in a partial or complete recovery. These relapses are the result of acute, monofocal or multifocal, inflammation, that is recurrent with the appearance of new injuries. Symptoms associated with a relapse include diplopia, dizziness and vertigo, paresthesia, optic neuritis, paraparesis, and pyramidal syndrome ${ }^{5}$. Progression is defined as a steadily increasing objectively documented neurological dysfunction/disability without unequivocal recovery (fluctuations and phases of stability may occur).

At present, several disease courses or phenotypes of MS have been identified ${ }^{6}$.

The clinical manifestations of MS, in both progression and relapses, include motor and sensory dysfunctions, accompanied by cognitive deficits and emotional, and/or psychiatric disorders ${ }^{7-9}$. Cognitive impairment has a high prevalence and has been reported in $43-70 \%$ of MS patients, and can occur at any stage of the disease $^{10}$. This cognitive dysfunction is a manifestation of axonal injury ${ }^{11,12}$ that is widely distributed throughout the brain and manifests as neuropsychological deficits, in attention, memory, learning, executive function, and processing speed. Using magnetic resonance imaging
(MRI) measures, Filippi et al. ${ }^{13}$ noted that cognitive impairment in MS is related to atrophy in the gray matter damage and Cruz-Gómez et al. ${ }^{14}$ suggest that low performance in episodic and declarative memory tasks is associated with reduced functional connectivity of the left hippocampus. Several studies ${ }^{15-18}$ show that cognitive deficits are present in the early stages of the MS, and the impairment include alterations in processes such as attention, memory, executive function, and processing speed. In the study carried out by Duque et al. ${ }^{11}$ they find the performance was worse for MS patients than for control participants in verbal memory tasks, working memory, and processing speed. Achiron et al..$^{19}$ and Desousa et al. ${ }^{20}$ reported on cognitive disturbances in memory, verbal fluency, attention, and processing speed in patients with MS. More specifically, after studying cognitive impairment among phenotypes of MS, Huijbregts et al. ${ }^{21}$ suggest that patients with different forms of MS are associated with different cognitive impairment profiles. Along the same lines, Wachowius et al. ${ }^{22}$ find that patients with progressive form of MS show greater cognitive impairment than patients with recurrent form of MS, and exhibit lower performance in tasks of visual memory, processing speed, and attention. Macías-Islas et al. ${ }^{23}$ assert that patients with relapsing-remitting MS (RRMS) perform significantly better in working memory, processing speed, and attention tasks than patients with primary progressive MS (PPMS). In short, it is necessary to know the involvement of the neuropsychological processes of each type of MS, to provide an adequate, early, and optimal neuropsychological intervention with the aim of delaying neurological disability and improving the quality of life of patients. For this reason, the objective of this research is to verify the existence of statistically significant differences in some neuropsychological processes such as attention, memory, language, visuoperceptual processing, executive function, 
and processing speed between patients with RRMS and PPMS.

\section{Methods}

A non-experimental descriptive and inferential design were used with the aim of describing the values of the study variables and comparing differences between groups (RRMS and PPMS). It was adopted an ex post facto and cross-sectional design, using a quantitative information-gathering methodology. The participants in this study were $20 \mathrm{MS}$ patients from patients from the Psyque Foundation in the City of Medellin, Colombia, between the ages of 22 and $52(M=37.40 ; D E=8.56)$, both sexes, 12 women and eight men. The RRMS group consisted of 11 patients, seven women, and four were men, aged between 22 and 46 (M: 37.55; DE: 6.54). The PPMS group consisted of nine patients, five women and four were men, aged between 22 and 52 (M: 37.27; DE: 10.24). All participants were of legal age and signed informed written consent expressing their agreement with participation in the study. The sample was non-random and the criteria for inclusion were as follows: to have MS diagnoses according to the McDonald criteria of 2005 (collected in Polman et al. ${ }^{24}$ ), to have a diagnosis time of the disease $<1$ year, to have at least one level of high school studies, and to belong to the Psyche Foundation of Medellin.

The exclusion criteria were illiteracy, perceptual alterations that prevented evaluation and psychiatric disorders or another neurological disease in the anamnesis; to verify the latter, the diagnosis report was requested from participants, with no additional tests being performed for the assessment of depression and anxiety that are common in MS patients. To verify that the intellectual level of participants was not $<70$, they were administrated K-BIT, which is an intelligence quotient (IQ) screening that verified that all patients had an IQ above 70, both the RRMS group (M: 76.22; SD: 16.81) and the PPMS group (M: 74.27; SD: 12.60).

The variables under study were attention, Wisconsin Cards Sorting test, Heaton, Chelune, Talley, Kay y Curtiss 31 this test evaluates cognitive flexibility. Memory, language, visuoperceptual processing, and executive function and processing speed, and the evaluation instruments for measuring them were, respectively: paced auditory serial addition test (PASAT) to evaluate auditory attention, symbol digit modalities test (SDMT) for auditory and visual attention, Rey Complex Figure Test (copy) for visual memory and visuoperceptual processing, Boston test to assess the naming abilities at a linguistic level and a verbal fluency test, the Wisconsin cards sorting test (WCST) to evaluate cognitive flexibility (one component of executive function), and Trail Making Test to assess processing speed.

The Paced Auditory Serial Addition Test (PASAT), Gronwall ${ }^{25}$ is a neuropsychological test used to assess divided attention; in this study the PASAT 3 version has been used.

The Symbol Digit Modalities Test (SDMT), Smith ${ }^{26}$ evaluates sustained attention and in the present research both versions (auditory and visual) have been used.

The Trail Making Test, Jarvis and Bart ${ }^{27}$ is used to assess attention and processing speed. In this study, only part B has been used and it has been registered the time spent performing the task.

Rey Complex Figure, $\operatorname{Rey}^{28}$ is a test that allows to assess the organization and visuospatial memory. In this study, the copy task is used to measure visuoperceptive ability and short-term visuospatial memory task.

The Boston test, Goodglass and Kaplan ${ }^{29}$ is used to assess naming abilities.

Verbal Fluency task, Ardila and Rosselli ${ }^{30}$ is a task of semantic verbal fluency.

Wisconsin Cards Sorting test (WCST), Heaton et al. ${ }^{31}$ : this test evaluates cognitive flexibility.

Before the assessment, informed consents were requested from participants of the Psyque Foundation of the City of Medellin, both RRMS and PPMS patients. Subsequently, the tests were clinically administered, i.e., a single researcher and patient in a ward.

The neuropsychological assessment was organized into three sessions of approximately $40 \mathrm{~min}$ each and the order of the tests remained constant for all patients. Lighting and loudness conditions were controlled in each room to make them the most optimal possible. The study was conducted in accordance with established ethical standards. The research was approved by the Bioethics Committee of the Pampuri Foundation - International NGO, in compliance with the ethical standards of the Helsinki Declaration of 2000.

The data were analyzed using the SPSS statistical program, version 20.0 for Windows. Descriptive statistics of the variables were calculated to represent the central tendency: mean, and standard deviation; and Student's parametric t-test, and Mann-Whitney's non-parametric U-test (after analysis of the Shapiro normality test) were used to check for significative differences between groups in the variables under study with a significance level $\alpha=0.05$. 
Table 1. Neuropsyhcological variables: inferential and descriptive results

\begin{tabular}{|l|c|c|c|c|c|c|}
\hline \multirow{2}{*}{ Neuropsychological variables } & \multicolumn{2}{|c|}{ EMRR } & \multicolumn{2}{|c|}{ EMPP } & \multirow{2}{*}{ t } \\
\cline { 2 - 6 } & Mean & Standard deviation & Mean & Standard deviation & \\
\hline Sustained visual attention & $21.18^{*}$ & 6.86 & $15.66^{*}$ & 7.63 & 1.700 & 0.10 \\
\hline Verbal fluency & $10.27^{*}$ & 3.10 & $10.11^{*}$ & 3.88 & 0.104 & 0.91 \\
\hline & & & & u & p \\
\hline Sustained auditory attention & $9.90^{*}$ & 6.73 & $7.77^{*}$ & 5.99 & 0.456 \\
\hline Divided auditory attention & $10.81^{*}$ & 6.46 & $5.33^{*}$ & 8.32 & 0.120 \\
\hline Processing speed & $239.27^{*}$ & 198.77 & $318.33^{*}$ & 231.25 & 0.456 \\
\hline Visual memory & $15.18^{*}$ & 9.16 & $8.33^{*}$ & 8.66 & 0.710 \\
\hline Denomination & $51.18^{*}$ & 8.48 & $44.88^{*}$ & 13.89 & 0.331 \\
\hline Visuoperceptual processing & $23.09^{*}$ & 6.68 & $16.66^{*}$ & 10.60 & 0.456 \\
\hline Executive function: cognitive flexibility & $4.27^{*}$ & 3.95 & $6.22^{*}$ & 6.34 & 0.710 \\
\hline
\end{tabular}

*Normal mean expected for the different tests: sustained auditory attention (48,38); sustained visual attention (42,97); divided auditory attention (48.3); processing speed (90.4); visual memory (14.1); denomination (44.2); verbal fluency (17.04); visuoperceptual processing (32); cognitive flexibility (5.7).

\section{Results}

The results of descriptive analyses of the attention, memory, language, visuoperceptual processing, executive function, and processing speed variables in the two EMRR and EMPP study groups are shown in table 1. The data in this table reveal a higher means for the variables sustained auditory attention, sustained visual attention, divided auditory attention, visual memory, denomination, and visuoperceptual processing in the patients RRMS. However, the mean of the variable cognitive flexibility is higher in PPMS. In processing speed RRMS patients used less time to finish the task. In the verbal fluency task, the performance of patients with RRMS and PPMS seems similar.

The results of the inferential analysis were obtained by Student's parametric t-test and Mann-Whitney's non-parametric U-test with a significance level of 0.05 , and show that there are no significant differences between EMRR and EMPP in any of the neuropsychological variables studied. Table 1 shows the results of the inferential analysis between RRMS and PPMS in all the neuropsychological measures.

To confirm the difference between MS patients and expected normal means, inferential statistics were in each of the neuropsychological tests with a significance level of 0.05 . The results using the Mann-Whitney $U$ test showed significant differences in sustained auditory attention $(p=0.000)$, divided auditory attention $(p=$ $0.000)$, processing speed $(p=0.000)$ and naming $(p=$
0.000). The comparative analysis using the Student $\mathrm{t}$-test found significant differences in verbal fluency $(\mathrm{t}=$ 8.212; $p=0.000)$ and sustained visual attention ( $t=$ 11.665; $p=0.000$ ). No significant differences were found in visual memory $(p=0.108)$, visuoperceptual processing $(p=0.602)$ and cognitive flexibility $(p=$ 0.602).

The differences between RRMS and PPMS were also analyzed based on age ( $t=0.072 ; p=0.944)$ intellectual level $(I Q)(p=0.421)$ and the schooling years $(t=1.201 ; p=0.245)$, and no significant differences were found.

The estimated sample size to find a significant difference has been calculated for the two variables closest to statistical significance: sustained visual attention and divided auditory attention. The number of participants estimated to find significant differences between groups with a $95 \% \mathrm{Cl}$ is 52 for sustained visual attention and 40 for divided auditory attention, half of each subtype.

\section{Discussion}

The results of the present study show that there are no significant differences between RRMS and PPMS in the neuropsychological processes evaluated in this research such as: attention, processing speed, memory, language, visuoperceptual processing, and cognitive flexibility. These findings are in line with previous studies $^{23}$ that found no significant differences in verbal 
fluency and executive function between RRMS and PPMS. However, these authors do find in their study that RRMS patients have better performance than PPMS patients in attention and processing speed tasks. In this same vein, Olivares et al. ${ }^{32}$ found significant differences between RRMS and PPMS in visual memory, attention, and processing speed tests. Johnen et al. ${ }^{33}$, in a meta-analysis of forty-seven empirical studies conducted with neuropsychological, found significant differences between PPMS and RRMS in favor of RRMS in $I Q$, speed processing, verbal learning, verbal memory, visual memory, working memory, cognitive fluency, visuoperception and executive function. These authors found that cognitive differences between MS subtypes persist regardless of clinical and demographic characteristics of the two subtypes, so they may be due to pathogenic differences or aspects related to the sample itself. In a systematic review of eighteen studies Vollmer et al. ${ }^{34}$ they highlight the relation between decreased brain volume with low scores on neuropsychological tests, suggesting that in PPSS there is a greater atrophy of the grey substance possibly generating decreased performance in neuropsychological tasks. Brochet y Ruet ${ }^{35}$ point out that the PPMS subtype presents more cognitive deficits than the RRMS subtype, specifically in tasks in memory, attention, processing speed, verbal fluency, executive functions, and working memory.

The lack of significant differences between RRMS and PPMS encountered in this research is not consistent with the expression of the two clinical profiles of MS. Several studies ${ }^{4}$ indicate that the progressive form of MS is more affected cognitively from the early stages of the disease than the recurrent form of MS, and therefore should be expected worse performance in neuropsychological tasks in those patients with PPMS since the onset of the disease.

However, the results of this research, conducted with a sample diagnosed less than a year ago, indicate that there are no differences in the first stage of the disease between patients with RRMS and PPMS in cognitive impairment in neuropsychological processes such as attention, processing speed, visual memory, language, visoperceptual processing, and executive function. The results suggest that in early moments, despite anatomical differences due to cortical loss and pathogenic factors typical of each subtype of MS, the performance of patients in neuropsychological tests is not affected, specifically, no significant differences were found among the patient group versus normal values in cognitive flexibility, visual memory and visuoperception tasks. This finding goes in the opposite direction than the results of the study conducted by Ruet et al. ${ }^{36}$, who found worse performance in patients with MS, both PPMS and RRMS subtypes, compared to control group, with more severe cognitive deficits in PPMS than in RRMS, due to pathogenic factors inherent in PPMS. In relation to language (naming), attention, processing speed, verbal fluency and $I Q$, the performance of patients diagnosed with MS is significantly lower than the mean of the normal population. These results are in line with those found by other studies ${ }^{33,37}$, suggesting that some cognitive domains are more impaired than others in the first months of the disease. It is true that the data obtained in the present study are conditioned by the sample size, due to the difficulty in finding participants who met the inclusion criteria, especially among patients who were diagnosed at most in 1 year, since the objective of the study was to check for differences between groups in neuropsychological impairment the onset of the disease. In addition, in this study, an attempt has been made to control the effect of the educational level, selecting patients with the same educational level (high school), since several studies ${ }^{38-40}$ have shown the effect of this factor on the performance of neuropsychological tests in patients with MS. Regarding the intellectual level $(\mathrm{IQ})$, there are no significant differences between the MS subtypes, in the opposite direction to the results found in other studies ${ }^{33,34,36}$. The present study raises the possibility that there are no different profiles of cognitive dysfunction in the execution of neuropsychological tests between RRMS and PPMS in patients with less than one year of symptoms. It is possible that the specific moment of the disease in the participants and the heterogeneity of measures of assessment of cognitive functioning used in the different studies may be influencing the results obtained.

This work has certain limitations: the size of the sample and lack of assessment of other variables that may affect the association of the clinical profile of MS and the cognitive impairment, such as cortical volume loss or white matter observed with MRI and the assessment of functional status or disability, preventing conclusion with a neuropsychiatric deterioration factor.

The results of this study may help the clinician in taking preventive decisions regarding the design and development of the neuropsychological rehabilitation plan of MS patients. The location of neuropsychological deficits in MS is essential to design intervention strategies for each MS subtype. In this study, despite having found no significant differences, the PPMS profile has a worse performance in neuropsychological tasks except for cognitive flexibility, which suggests the early 
need for more specialized treatment than the RRMS profile. It could be considered whether an early cognitive intervention in the first months could decrease the difference in terms of cognitive impairment in patients with PPMS versus the RRMS subtype.

\section{Conclusion}

In short, this study provides information on the neuropsychological differences between RRMS and PPMS in the initial phase of the disease and about the early neuropsychological profile of both types of MS.

Overall, RRMS patients have better scores on all neuropsychological measures (except cognitive flexibility), although the differences do not become significant in the sample under study. These results may indicate that RRMS/PPMS patients do not differ significantly from each other in the execution of neuropsychological processes in the $1^{\text {st }}$ year after diagnosis. It is important to highlight that the participants of the two groups of MS subtypes in this study are both in the initial stage of the disease (diagnosed for less one year), and they have similar educational level, age, years of schooling and IQ. This data can help by providing information on the status of early-stage cognitive processes of both phenotypes and clinical forms of MS, as an indicator of prognosis and to suggest therapeutic and follow-up strategies in patients with RRMS/PPMS.

As a proposal for future research, it is important to increase the size of the sample and select patients with RRMS and PPMS with more years of disease evolution so that it can be compared the differences between the two types of MS patients in neuropsychological decline, with the passage of time and the effect of medication.

\section{Funding}

The present investigation has not received any specific scholarship from the public, commercial, or non-profit agencies.

\section{Conflicts of interest}

None.

\section{Ethical disclosures}

Protection of human and animal subjects. The authors declare that no experiments were performed on humans or animals for this study.
Confidentiality of data. The authors declare that they have followed the protocols of their work center on the publication of patient data.

Right to privacy and informed consent. The authors declare that no patient data appear in this article.

\section{References}

1. Shultheis MT, Garay E, Deluca J. The influence of cognitive impairment on driving performance in multiple sclerosis. Neurology. 2001;56:1089-94.

2. Sánchez JL, Aguirre C, Arcos-Burgos M, Jiménez-Ramírez I, Jiménez ME, León-Sarmiento FE, et al. Prevalencia de la esclerosis múltiple en Colombia. Rev Neurol. 2000;31:1101-3.

3. Sánchez-Chaparro MM, Rodríguez-Sánchez IP, Barrera-Saldaña HA Martínez-Villarreal LE, Resendez-Pérez D, Gámez-Escobedo IA. MicroARN y sus mecanismos neuroinmunorreguladores en la esclerosis múltiple. Desarrollo de biomarcadores para su diagnóstico. Rev Neurol. 2015;60:562-71

4. Boscá I, Casanova B. Esclerosis múltiple. Una visión general. GH Continuada. 2007;6:147-50.

5. Ghasemi N, Razavi S, Nikzad E. Multiple sclerosis: pathogenesis, symptoms, diagnoses and cell-based therapy. Cell J. 2017;19:1-10.

6. Lublin F, Reingold S, Cohen J, Cutter G, Sorensen P, Thompson A. Defining the clinical course of multiple sclerosis. The 2013 revisions. Neurology 2014;83:278-86.

7. Chiaravalloti N, Deluca J. Cognitive impairment in multiple sclerosis. Lancet Neurol. 2008;7:1139-51.

8. Pozuelo-Moyano B, Benito-León J. Trastornos afectivos y psicóticos en la esclerosis múltiple. Rev Neurol. 2015;61:503-8.

9. Chabas D, Fontaine B, Lyon-Caen O. Multiple Sclerosis. France: Orphanet Encyclopedia; 2004

10. Olascoaga J. Calidad de vida y esclerosis múltiple. Rev Neurol. 2010;51:279-88.

11. Duque $P$, Oltra-Cucarella J, Fernández $O$, Sepulcre J. Batería neuropsicológica breve en la esclerosis múltiple. Baremación normativa estratificada por edad y nivel educativo. Rev Neurol. 2017;64:97-104.

12. Hoogs M, Morrow S, Benedict RH. Utility of routine neuropsychological assessment for early identification of cognitive impairment in MS. Int MS J. 2010;17:6-11.

13. Filippi M, Rocca MA, Benedict RH, DeLuca J, Geurts JJ, Rombouts SA, et al. The contribution of MRI in assessing cognitive impaiment in multiple sclerosis. Neurology. 2010;75:2121-8.

14. Cruz-Gómez A, Belenguer-Benavides A, Martínez-Bronchal B, Fitipaldi-Márquez MS, Forn C. Cambios estructurales y funcionales del hipocampo en pacientes con esclerosis múltiple y su relación con procesos de memoria. Rev Neurol. 2017;62:6-12.

15. Feuillet L, Reuter F, Audoin B, Malikova I, Barrau K, Cherif AA, et al. Early cognitive impairment in patients with clinically isolated syndrome suggestive of multiple sclerosis. Mult Scler. 2007;13:124-7.

16. Khalil M, Enzinger C, Langkammer C, Petrovic K, Loitfelder M, Tscherner $\mathrm{M}$, et al. Cognitive impairment in relation to MRI metrics in patients with clinically isolated syndrome. Mult Scler J 2011;17:173-80.

17. Longoni G, Rocca MA, Pagani E, Riccitelli GC, Colombo B, Falini A, et al. Deficits in memory and visuospatial learning correlate with regional hippocampal atrophy in MS. Brain Struct Funct. 2015;220:435-44.

18. Sicotte NL, Kern KC, Giesser BS, Arshanapalli A, Schultz A, Montag M, et al. Regional hippocampal atrophy in multiple sclerosis. Brain. 2008;46:664-6.

19. Achiron A, Polliack M, Rao SM, Barak Y, Lavie M, Appelboim N, et al. Cognitive patterns and progression in multiple sclerosis: construction and validation of percentile curves. J Neurol Neurosurg Psychiatry. 2005;76:744-9.

20. DeSousa EA, Albert RH, Kalman B. Cognitive impairments in multiple sclerosis: a review. Am J Alz Dis Dem. 2002;17:23-9.

21. Huijbregts SC, Lalkers NF, Sonneville LM, de Groot V, Reuling IE, Polman CH. Differences in cognitive impairment of relapsing remitting, secondary and primary progressive multiple sclerosis. Neurology. 2004;63:335-9.

22. Wachowius U, Talley M, Silver N, Heinze HJ, Sailer M. Cognitive impairment in primary and secondary progressive sclerosis. J Clin Exp Neuropsychol. 2005;27:65-77.

23. Macías-Islas MA, Aguayo-Arelis A, Rábago BV, Velázquez M, Martínez-Tapia ME, Arango-Lasprilla JC. Deterioro cognitivo en pacientes con esclerosis múltiple del occidente de México. Rev Mex Neuroci 2015;16:1-12.

24. Polman $\mathrm{CH}$, Reingold SC, Edan G, Filippi M, Hartung HP, Kappos L, et al. Diagnostic criteria for multiple sclerosis: 2005 revisions to the McDonald criteria. Ann Neurol. 2005;58:840-6. 
Rev Mex Neuroci. 2020;21(5)

25. Gronwall D. Paced auditory serial-addition task: a measure of recovery from concussion. Percept Mot Skills. 1977;44:367-73.

26. Smith A. SDMT. Test de dígitos y símbolos. Madrid: TEA; 2012.

27. Jarvis P, Bart J. The Halstead Reitan Neuropsychological Battery. Florida: Psychological Assessment Resources; 1994.

28. Rey A. Test de Copia y de Reproducción de Memoria de Figuras Geométricas Complejas; 1997. Madrid: TEA; 1997.

29. Goodglass H, Kaplan E. Evaluación de la Afasia y de Trastornos Similares. Buenos Aires: Médica Panamericana; 1979.

30. Ardila A, Rosselli M. Neuropsicología Clínica. Bogotá: Prensa Creativa 1992

31. Heaton R, Chelune G, Talley J, Kay G, Curtiss G. Test de clasificación de tarjetas de Wisconsin. Manual. Madrid: TEA Ediciones; 2001.

32. Olivares T, Nieto A, Sánchez MP, Wollmann T, Hernández MA, Barroso J. Pattern of neuropsychological impairment in the early phase of relapsing-remitting multiple sclerosis. Mult Scler 2005;11:191-7.

33. Johnen A, Landmeyes NC, Bürkner P-C, Wiendl H, Meuth SG, Holling H Distinct cognitive impairments in different disease courses of multiple sclerosis. A systematic review and meta-analysis. Neurosci Biobehav Rev. 2017;83:568-78
34. Vollmer T, Huynh L, Kelley C, Galebach P, Signorovitch J, DiBernardo A, Sasane R. Relationship between brain volume loss and cognitive outcomes among patients with multiple sclerosis: a systematic literature review. Neurol Sci. 2016;37:165-79.

35. Brochet B, Ruet A. Cognitive impairment in Multiple Sclerosis with regards to disease duration and clinical phenotypes. Front Neurol. 2019;10:261.

36. Ruet A, Deloire M, Charré-Morin J, Hamel D, Brochet B. Cognitive impairment differs between primary progressive and relapsing-remitting MS. Neurology 2013;80:1501-8.

37. Chiaravalloti ND, DeLuca J. Cognitive impairment in Multiple Sclerosis. Lancet Neurol. 2008;7:1139-51.

38. Pinter D, Sumowski J, DeLuca J, Fazekas F, Pichler A, Khalil M, et al. Higher education moderates the effect of T2 lesion load and third ventricle width on cognition in multiple sclerosis. Plos One. 2014;9(1):e87567.

39. Scarpazza C, Braghittoni D, Casale B, Magalú S, Mattiolo F, Di Pellegrino $G$, et al. Education protects against cognitive changes associated with multiple sclerosis. Restor Neurol Neurosci. 2013:31:619-31.

40. Sumowski JF, Leavitt VM. Cognitive reserve in multiple sclerosis. Mult Scler Journal. 2013;19:1122-27. 